\title{
Rehujen rikkipitoisuuksista
}

\author{
Matti Kreula ja Terttu Ettala \\ Biokemiallinen Tutkimuslaitos, Kalevank. 56 b, 00180 Helsinki 18
}

\section{Sulphur contents of fodders}

\author{
Matri Kreula and Terttu Ettala \\ Biochemical Research Institute, Kalevank. 56 B. 00180 Helsinki 18
}

\begin{abstract}
Total sulphur determinations were made on grass (60 samples), hay (125), ensilage (857), oats (40) and barley (40), obtained from various parts of Finland. Sulphur was also determined on samples of grass (36) and ensilage (76) received from the Lintupaju experimental farm in Jokioinen. The ratio total nitrogen: total sulphur was also determined.

The grass samples from various parts of the country contained $0.16 \pm 0.04 \%$ sulphur, the ensilage samples $0.14 \pm 0.05 \%$ and the hay samples $0.09 \pm 0.01 \%$ of the dry matter. The grass samples obtained from the Lintupaju experimental farm contained $0.20 \pm 0.03 \%$ and the ensilage samples $0.18 \pm 0.03 \%$ sulphur of the dry matter. As the silages were made using sulphur-containing preservatives, the average sulphur content was $0.48 \%$ of the dry matter. Statistically significant differences $(\mathrm{P}<0.001)$ were observed in the sulphur contents of ensilages obtained from various parts of the country. The sulphur content of the oats samples was $0.07 \%$ of the dry matter and that of the barley samples $0.06 \%$.

The average ratio between nitrogen and sulphur was 19.1 in the grass samples, 18.1 in the ensilage samples and $\mathbf{1 7 . 8}$ in the hay samples. In silages made with sulphurcontaining preservatives, the nitrogen: sulphur ratio was 6.5 . In oats the ratio was on the average 30.0 and in barley 35.0 .
\end{abstract}

\section{Johdanto}

Rikki kuuluu niihin alkuaineisiin, joita kasvit ja eläimet välttämättä tarvitsevat. Sekä NRC (1971) että NJF:n asettama toimikunta (1975) ovat suositelleet rehun rikkipitoisuudeksi lypsylehmillä $0.20 \%$, lihakarjalla ja lampailla $0.10 \%$ kuiva-aineesta. Märehtijöiden päivittäin tarvitseman rikin määrää ei kirjallisuudessa ole täsmällisesti voitu esittää, koska siihen vaikuttavat monet tekijät. Niinpä esimerkiksi typen ja rikin suhdetta rehuissa pidetään tärkeänä, ja BIRD (1974) on pitänyt suhdetta 15: 1 lehmille sopivana.

Rehujen rikkipitoisuutta on Suomessa aikaisemmin tutkittu timoteiheinän, ohran ja kauran osalta. SALONEN ym. (1962) ovat määrittäneet rikin rannikkoalueilla ja muualla maassa kasvaneesta timoteiheinästä ja OKSANEN (1965) 
Pohjanmaan sulfaattimailla kasvaneista ohrasta, kaurasta ja timoteiheinäsłä. Kun kuitenkin rikkilannoituksen määrä KoRKMANin (1973) mukaan on huomattavasti vähentynyt, eikä säilörehujen rikkipitoisuuksista ole ollut mitään tietoa, on haluttu selvittää rehujen tämänhetkistä rikkitilannetta. Tässä työssä on eri puolilta Suomea kerätyistä näytteistä määritetty kokonaisrikki ja vähäisemmässä määrässä sulfaattirikki säilörehuista, ruohoista, heinistä, kauroista ja ohrista sekä laskettu typen ja rikin suhde asianomaisissa rehuissa.

\section{Aineisto ja menetelmät}

Rehunäytteitä on kerätty satunnaisesti valituilta maatiloilta eri puolilta Suomea. Säilörehunäytteitä on ollut vuodelta 197459 ja vuodelta 1975798 näytettä, ruohonäytteitä vastaavasti 28 ja 32 sekä heinänäytteitä vuodelta 1975105 ja vuodelta 197620 yhteisnäytettä, joista kukin on sisältänyt 20 maatilan heinää. Lisäksi on tutkittu 36 ruoho- ja 55 säilörehunäytettä Jokioisten Lintupajun koetilalta. Myös rikkipitoisilla säilöntäaineilla säilötyistä rehuista on otettu 21 näytettä Lintupajun koetilalta. Kauraa ja ohraa on kerätty Varsinais-Suomesta, Satakunnasta, Pohjois-Savosta ja Pohjois-Karjalasta, kustakin 10 näytettä.

Rehut eivät ole olleet täysin tasalaatuisia, koska ne ovat vaihdelleet kasvilajien ja kasvuasteen suhteen. Varsinkin säilörehuissa ovat myös tuhkapitoisuudet vaihdelleet suuresti. Tämä on ilmeisesti johtunut siitä, että rehuihin on sekoittunut korjuun yhteydessä multaa (LindFors ym. 1976).

Rehunäytteet on kuivattu ja jauhettu. Rikkimääritykset on tehty BIRDin ja Fountarnin (1970) menetelmällä. Kokonaistyppi kauroista ja ohrista on määritetty Kjeldahl-menetelmällä BEETin (1955) mukaan. Ruohoista, heinistä ja säilörehuista on kokonaistyppimääritykset tehty Maatalouden tutkimuskeskuksen laboratoriossa Tikkurilassa.

\section{Tulokset}

Ruohoissa ovat kokonaisrikkimäärät olleet jonkin verran korkeammat $(0.16 \pm 0.04 \%$ kuiva-aineesta) kuin säilörehuissa $(0.14 \pm 0.05 \%$ kuiva-aineesta). Koeolosuhteissa kasvatettu ruoho ja siitä tehty säilörehu ovat sisältäneet rikkiä enemmän kuin koko maan rehunäytteet keskimäärin. Heinien keskimääräinen rikkipitoisuus on ollut alhaisempi kuin ruohojen ja säilörehujen (Taulukko 1). Sulfaattirikin osuus on ollut keskimäärin $9.0 \%$ kokonaisrikistä. Jos säilörehujen valmistuksessa on käytetty rikkipitoisia säilöntäaineita, on rehuissa ollut rikkiä keskimäärin $0.48 \%(0.32-0.74 \%)$ kuiva-aineesta. Tästä määrästä on ollut keskimäärin $19.0 \%$ sulfaattirikkiä. Eri säilöntäaineiden, mikäli ne eivät ole sisältäneet rikkiä, ei ole todettu vaikuttaneen rehujen rikkipitoisuuksiin.

Rehujen kasvuaste on jonkin verran vaikuttanut rikkipitoisuuteen. Kasvin vanhetessa on rikkipitoisuus alentunut (Taulukko 2). Säilörehuista ensimmäinen sato on sisältänyt rikkiä vähemmän kuin toinen ja kolmas sato. Säilörehujen rikkipitoisuus on ollut korkea, jos rehut ovat sisältäneet runsaasti tuhkaa (Taulukko 3). Kuva 1 esittää säilörehujen jakautumista rikki- 
Taulukko 1. Keskimääräinen kokonaisrikkipitoisuus sekä typen ja rikin suhde ruohossa, säilörehussa ja heinässä.

Table 1. Average total sulphur content and nitrogen: sulphur ratio in grass, ensilages and hay.

\begin{tabular}{lccc}
\hline Rehu & Näytteitä & Rikkiä \%/ka & N:S \\
Feed & No. of & Sulphur & N:S \\
& samples & $\% /$ d.m. & \\
\hline
\end{tabular}

Näytteet koko maasta:

Samples from the whole country:

\begin{tabular}{|c|c|c|c|c|}
\hline Ruoho 1974 & - Grass 1974 ... & 28 & $0.16 \pm 0.03$ & $20.4 \pm 3.8$ \\
\hline Ruoho 1975 & - Grass 1975 ................ & 32 & $0.16 \pm 0.04$ & $17.8 \pm 3.0$ \\
\hline Säilörehu 1974 & Ensilage 1974 .............. & 59 & $0.14 \pm 0.03$ & $18.1 \pm 4.4$ \\
\hline Säilörehu 1975 & - Ensilage 1975 ......... & 798 & $0.14 \pm 0.05$ & \\
\hline Heinä 1975 & Hay 1975 ................. & 105 & $0.09 \pm 0.01$ & $7.8 \pm 2.5$ \\
\hline Heinä 1976 & Hay 1976 & $\left.20^{1}\right)$ & $0.09 \pm 0.01$ & \\
\hline
\end{tabular}

Näytteet Lintupajusta:

Samples from the Lintupaju farm:

Ruoho 1974 - Grass $1974 \ldots \ldots \ldots \ldots \ldots . . . .36 \quad 36 \quad 0.20 \pm 0.03$

Säilörehu 1974 - Ensilage $1974 \ldots \ldots \ldots . .55 \quad 55 \quad 0.18 \pm 0.03 \quad 16.1 \pm 0.04$

Säilörehu, säilöntäaineessa rikkiä ….... $21 \quad 0.48 \pm 0.10 \quad 6.5 \pm 1.6$

Ensilage, made with sulphur-

containing preservative

1) Jokainen näyte on sisältänyt 20 maatilan heinää.

1) Each sample contained hay from 20 farms.

Taulukko 2. Kasvuasteen vaikutus rehun rikkipitoisuuteen.

Table 2. Effect of stage of growth on sulphur content of feed

\begin{tabular}{|c|c|c|}
\hline $\begin{array}{l}\text { Kasvuaste } \\
\text { Stage of growth } \\
\end{array}$ & $\begin{array}{c}\text { Näytteitä } \\
\text { No. of samples }\end{array}$ & $\begin{array}{c}\text { Rikkiä } \% / \text { ka. } \\
\text { Sulphur } \% / d . m\end{array}$ \\
\hline Ennen tähkälle tuloa - Before heading ...................... & 286 & $0.14 \pm 0.06$ \\
\hline Tähkimisen alussa $-A t$ the beginning of heading ......... & 355 & $0.14 \pm 0.04$ \\
\hline Noin puolet tähkällä - About half headed ................. & 114 & $0.13 \pm 0.03$ \\
\hline Täydellisesti tähkällä - In full heading .................... & 24 & $0.12 \pm 0.06$ \\
\hline
\end{tabular}

Taulukko 3. Vuoden 1975 säilörehujen rikkipitoisuudet eri tuhkapitoisuuksien mukaan. Table 3. Sulphur content of silages in 1975 according to ash content.

\begin{tabular}{ccc}
\hline $\begin{array}{c}\text { Näytteitä } \\
\text { No. of samples }\end{array}$ & $\begin{array}{c}\text { Tuhkaa \%/ka } \\
\text { Ash \%/d.m. }\end{array}$ & $\begin{array}{c}\text { Rikkiä \%/ka } \\
\text { Sulphur \%/d.m. }\end{array}$ \\
\hline & $<5.0$ & $0.13 \pm 0.05$ \\
338 & $5.0-6.9$ & $0.13 \pm 0.03$ \\
266 & $7.0-8.9$ & $0.14 \pm 0.05$ \\
77 & $9.0-10.9$ & $0.15 \pm 0.05$ \\
69 & $\geqq 11.0$ & $0.17 \pm 0.07$ \\
\hline
\end{tabular}




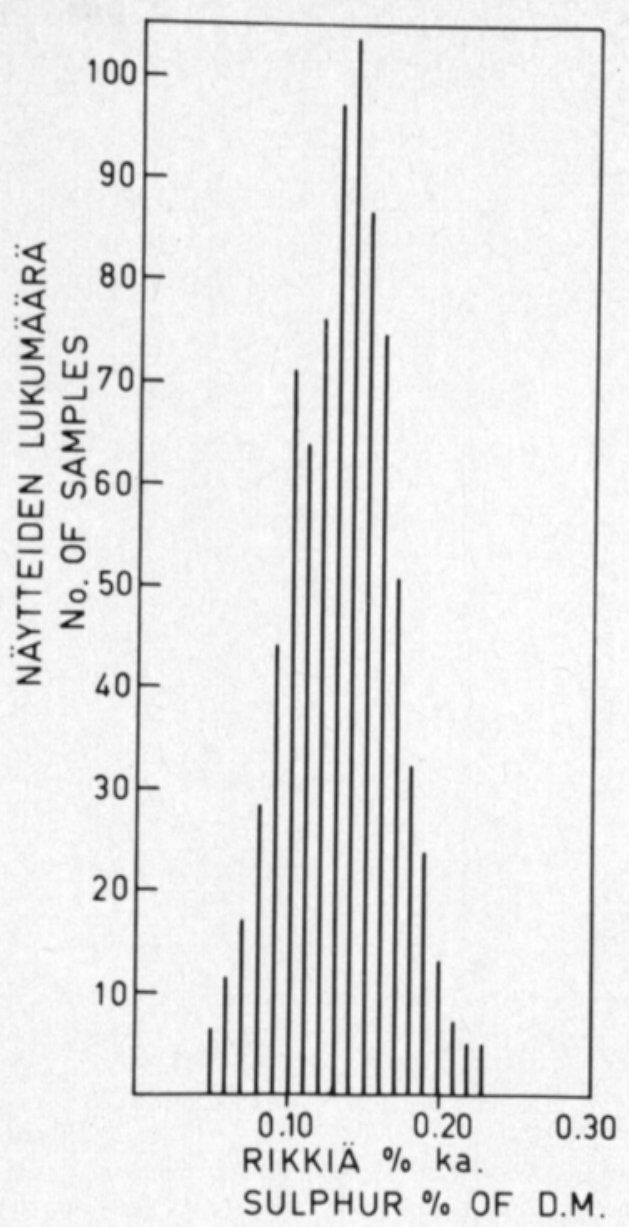

Kuva 1. Säilörehujen jakautuma rikkipitoisuuksien mukaan.

Fig. 1. Distribution of silages according to their sulphur contents.

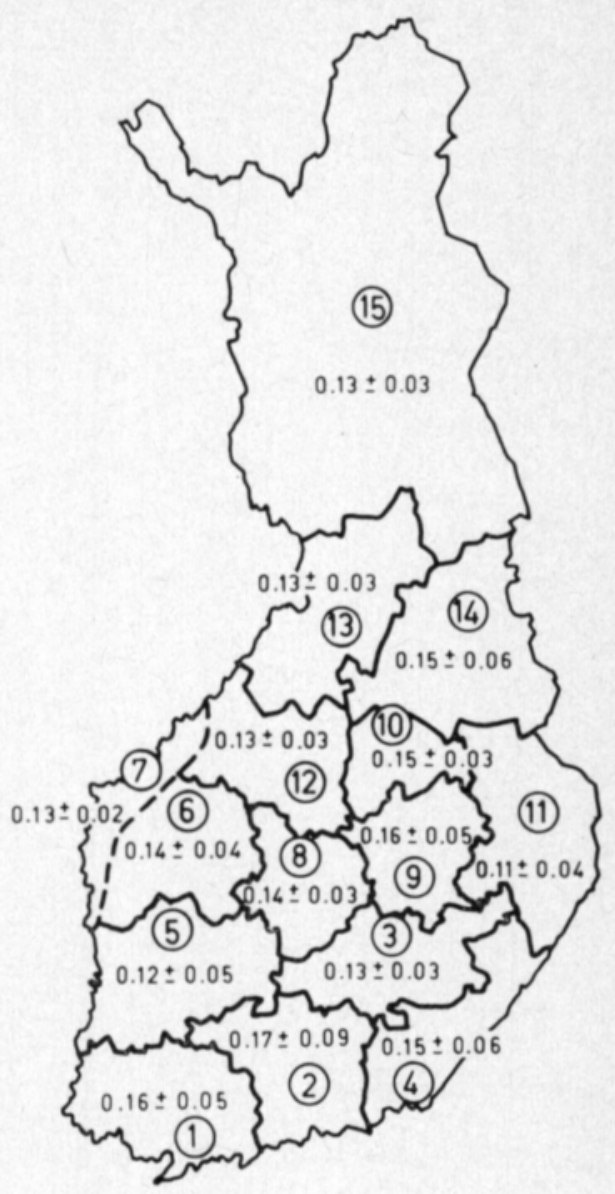

Kuva 2. Säilörehujen keskimääräiset rikkipitoisuudet maan eri osissa.

Fig. 2. Average sulphur contents of silages in various parts of Finland.

pitoisuuksien mukaan. Eri osissa maata säilörehujen keskimääräiset rikkipitoisuudet poikkeavat toisistaan (Kuva 2). Pohjois-Karjalassa ja Satakunnassa Mouhijärven-Lavian alueella ne ovat olleet alhaisemmat ja Etelä-HämeenUudenmaan alueella, Varsinais-Suomessa ja Pohjois-Savossa suuremmat kuin muualla maassa. Erot ovat olleet tilastollisesti merkitseviä $(\mathrm{P}<0.001)$.

Typen ja rikin suhde on ruohoissa ollut keskimäärin 19.0, säilörehuissa 18.1 ja heinissä 17.8. Lintupajun koetilan säilörehunäytteissä on typen ja rikin suhde ollut 16.1. Rikkipitoisilla säilöntäaineilla säilötyissä rehuissa on typen ja rikin suhde ollut keskimäärin 6.5 (Taulukko 1).

Kauranäytteiden keskimääräinen rikkipitoisuus on ollut 0.07 ja ohranäytteiden $0.06 \%$ kuiva-aineesta (Taulukko 4). Alueelliset erot ovat olleet tilastollisesti merkitseviä sekä kauran $(\mathrm{P}<0.01)$ että ohran $(\mathrm{P}<0.05)$ osalta. Typen ja rikin suhteessa ero on ollut merkitsevä kauran $(\mathrm{P}<0.01)$, muttei ohran osalta. Satakunnan alueen kaura- ja ohranäytteet ovat sisältäneet rikkiä keskimäärin vähemmän kuin muiden rikkimäärityksissä mukana olleiden alueiden näytteet. 
Taulukko 4. Kauran ja ohran keskimääräiset rikkipitoisuudet sekä typen ja rikin suhteet eri puolilla Suomea.

Table 4. Average sulphur content and nitrogen: sulphur ratio of oats and barley in various parts of Finland.

\begin{tabular}{|c|c|c|c|c|}
\hline & $\begin{array}{l}\text { Alue }^{1} \text { ) } \\
\text { Area }^{1} \text { ) }\end{array}$ & $\begin{array}{c}\text { Näytteitä } \\
\text { No. of samples }\end{array}$ & $\begin{array}{c}\text { Rikkiä } \% / \text { ka } \\
\text { Sulphur \%/d.m. }\end{array}$ & $\mathrm{N}^{*}: \mathrm{S}$ \\
\hline \multicolumn{5}{|l|}{$\begin{array}{l}\text { Kaurat: } \\
\text { Oats: }\end{array}$} \\
\hline 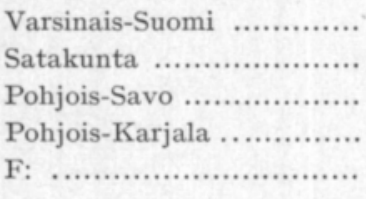 & $\begin{array}{r}1 \\
5 \\
10 \\
11\end{array}$ & $\begin{array}{l}10 \\
10 \\
10 \\
10\end{array}$ & $\begin{array}{l}0.076 \pm 0.010 \\
0.059 \pm 0.007 \\
0.073 \pm 0.012 \\
0.070 \pm 0.011 \\
5.31 * *\end{array}$ & $\begin{array}{l}27.0 \pm 4.8 \\
34.1 \pm 4.4 \\
28.9 \pm 4.3 \\
29.8 \pm 3.7 \\
4.91 * *\end{array}$ \\
\hline \multicolumn{5}{|l|}{$\begin{array}{l}\text { Ohrat: } \\
\text { Barley: }\end{array}$} \\
\hline 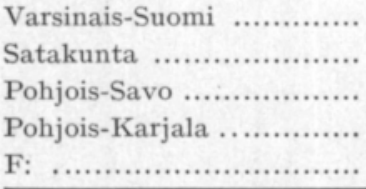 & $\begin{array}{r}1 \\
5 \\
10 \\
11\end{array}$ & $\begin{array}{l}10 \\
10 \\
10 \\
10\end{array}$ & $\begin{array}{l}0.053 \pm 0.006 \\
0.050 \pm 0.007 \\
0.062 \pm 0.009 \\
0.058 \pm 0.012 \\
3.15^{*}\end{array}$ & $\begin{array}{c}34.0 \pm 4.3 \\
35.7 \pm 7.3 \\
32.9 \pm 5.3 \\
37.9 \pm 7.3 \\
1.5\end{array}$ \\
\hline
\end{tabular}

1) Aluejako kuvassa 2.

1) See Fig. 2.

\section{Tulosten tarkastelu}

Tarkasteltaessa saatuja tuloksia aikaisempien tulosten valossa on todettava, että tässä työssä on saatu heinille alhaisempia rikkipitoisuuksia $(0.09 \pm 0.01 \%$ kuiva-aineesta) kuin mitä SALONEN ym. (1962) ovat saaneet $(0.13-0.18 \%$ kuiva-aineesta). Myös OKSANEN (1965) on todennut heinien sisältäneen rikkiä keskimäärin $0.14 \%$ kuiva-aineesta. OKSASEN mukaan ovat myös kaura $(0.15 \%)$ ja ohra $(0.18 \%)$ sisältäneet rikkiä paljon runsaammin kuin nyt tutkitut viljat. KORKMAN (1973) on saanut kenttäkokeessa viljellyn ohran rikkipitoisuudeksi $0.10 \%$ kuiva-aineesta, mikä on jo ollut vähemmän kuin OKSASEN (1965) tutkimissa ohrissa. Tässä nyt esiteltävässä työssä ei ole ollut vilja- eikä rehunäytteitä Pohjanmaan rikkipitoisilta mailta. joten suoranaista vertailukohdetta ei ole ollut. Toisaalta ovat SALONEN ym. (1962) todenneet, ettei sulfaattimaiden ja muiden maiden kasvien rikkipitoisuuksissa ole ollut suuria eroja. Lintupajun koetilan ruohot, samoin kuin niistä valmistetut säilörehutkin, ovat sisältäneet rikkiä enemmän kuin koko maan rehut keskimäärin ja myöskin enemmän kuin Varsinais-Suomen ja Etelä-Hämeen maatilojen rehut. Nämä rehut ovat kuitenkin poikenneet rikkipitoisuuden suhteen Lintupajun koetilan rehuista vähemmän kuin koko maan rehut.

Verrattaessa saatuja rikkipitoisuuksia niihin lukuihin, joita NRC:n ja NJF:n asiantuntijaryhmä ovat rikin tarpeesta esittäneet, nimittäin lypsylehmille $0.20 \%$ ja lihakarjalle ja lampaille $0.10 \%$ kuiva-aineesta, voidaan todeta, etteivät tutkitut rehut, harvoja yksittäisiä poikkeuksia lukuunottamatta, ole sisältäneet rikkiä suositeltua määrää. Toisaalta on todettu, että rikkitasa- 
paino on lypsylehmillä (maitoa $8-37 \mathrm{~kg} / \mathrm{pv}$ ) säilynyt, kun rehujen rikkipitoisuus on ollut $0.12 \%$ kuiva-aineesta (Bouchard ja Conrad 1973). Nyt tutkituista rehuista ainoastaan Lintupajun koetilan rehujen typen ja rikin suhde on ollut lähellä BrRDin (1974) nautakarjalle suosittelemaa suhdetta $(15.0: 1.0)$. Muissa rehuissa suhteet ovat olleet jonkin verran liian korkeat, nimittäin ruohossa keskimäärin 19.0, säilörehuissa 18.1 ja heinissä 17.8. Kaucan ja ohran osalta typen ja rikin suhteet ovat olleet vielä korkeammat ja siis todennäköisesti eläinten ravitsemuksen kannalta epäedullisemmat.

Rikkipitoisilla säilöntäaineilla säilötyt rehut ovat sisältäneet rikkiä muita rehuja huomattavasti enemmän, nimittäin $0.48 \%$ kuiva-aineesta. Niinikään typen ja rikin suhde on ollut alhainen keskimääräisen arvon ollessa 6.5. Vaikka eräät tutkijat (CHALUPA ym. 1971, 1973) ovat voineet syöttää eläimille runsaasti rikkiä ilman häiriöitä, on toisaalta todettu liiallisen syöttämisen olleen haitallista. Rehujen korkean rikkipitoisuuden on todettu häiritsevän eräiden hivenaineiden, mm. seleenin (Hintz ja Hogue 1964) ja kuparin (Huisingh ym. 1973) hyväksikäyttöä ja siten aiheuttavan niiden puutetta. Näin ollen mm. ELAM (1975) on kehoittanut varovaisuuteen yli $0.3 \%$ rikkiä sisältävien rehujen suhteen. Toisaalta on otettava huomioon, että eläimille syötetään useimmissa tapauksissa säilörehun ohella myös viljaa ja heinää. Tällöin koko syötettävän rehun keskimääräinen rikkipitoisuus alenee.

Maan eri osista otetuista säilörehunäytteistä voidaan todeta, että PohjoisKarjalasta ja Satakunnasta saadut näytteet ovat sisältäneet rikkiä koko maan keskiarvoa vähemmän. Pohjois-Karjalassa ei näitä alhaisia rikkipitoisuuksia ole voitu paikallistaa minkään määrätyn kunnan alueelle, mutta Satakunnassa ovat vähän rikkiä sisältäneet rehut löytyneet Mouhijärven ja Lavian kuntien alueelta. Sen sijaan esimerkiksi Lauttakylästä ja Tampereen seudulta saadut rehunäytteet ovat sisältäneet rikkiä koko maan keskiarvoa vastaavan määrän tai sitä enemmän. Kaura- ja ohranäytteitä on tutkittu Varsinais-Suomesta, Satakunnasta, Pohjois-Savosta ja Pohjois-Karjalasta. Näytteitä on ollut vain 10 kultakin alueelta, mutta niissäkin tulokset ovat olleet samansuuntaisia kuin säilörehuissa. Mouhijärven-Lavian seudun kaurat ja ohrat ovat sisältäneet rikkiä vähemmän kuin muut tutkitut viljanäytteet. Näihin alhaisiin rikkipitoisuuksiin on rikkilannoituksen vähenemisen ohella voinut vaikuttaa itse maaperän alhainen rikkipitoisuus.

Edellä esitetyn mukaan kotieläinten rikin saannissa voi esiintyä niukkuutta yksittäisissä tapauksissa, vaikka koko maan keskimääräiset rikkipitoisuudet eivät olekaan hälyttävän alhaisia. Rikin niukkuutta voi esiintyä varsinkin karjoissa, joissa on vilja-heinäruokinta vallitsevana. Ehkä eräillä alueilla olisi syytä kiinnittää huomiota rikkilannoitukseen kasvien optimikasvun ja parhaan proteiinituotannon kannalta.

\section{Tiivistelmä}

Rehujen rikkitilanteen selvittämiseksi on eri puolilta Suomea satunnaisesti valituilta maatiloilta määritetty ruohoista (60 näytettä), säilörehuista (857 näytettä), heinistä (125 näytettä), kauroista (40 näytettä) ja ohrista (40 näy- 
tettä) kokonaisrikki ja osasta näytteitä myös sulfaattirikki. Lisäksi on Jokioisten Lintupajun koetilalta määritetty rikki 55 säilörehunäytteestä, 36 ruohonäytteestä ja 21 näytteestä säilörehuja, joiden säilöntäaineet ovat sisältäneet rikkiä.

Koko maan ruohonäytteet ovat sisältäneet rikkiä $0.16 \pm 0.04 \%$, säilörehut $0.14 \pm 0.05 \%$ ja heinät $0.09 \pm 0.01 \%$ kuiva-aineesta. Lintupajun ruoho on sisältänyt rikkiä $0.20 \pm 0.03 \%$ ja siitä tehty säilörehu $0.18 \pm 0.03 \%$ kuiva-aineesta. Kun säilörehut on tehty rikkiä sisältävillä säilöntäaineilla, on rehun keskimääräinen rikkipitoisuus ollut $0.48 \%$ kuiva-aineesta. Säilörehujen osalta on todettu eroavuuksia maan eri osien välillä. Kauranäytteiden kuivaaineesta on ollut rikkiä $0.07 \%$ ja ohranäytteiden $0.06 \%$.

Typen ja rikin keskimääräinen suhde on ollut ruohossa 19.1, säilörehussa 18.1 ja heinässä 17.8. Rikkiä säilöntäaineessa käytettäessä on typen ja rikin suhde säilörehiussa ollut 6.5. Kaurassa on typen ja rikin suhde ollut keskimäärin 30.0 ja ohrassa 35.0 .

\section{KIRJALLISUUS}

BeEt, A. E. 1955. Potassium permanganate in the Kjeldahl method for the determination of nitrogen in organic substances. Nature 175: $513-514$.

Bird, P. R. \& Fountarn, R. D. 1970. A method for the determination of sulfur in some biological materials. Analyst 95: 98-102.

- -1974 . Sulphur metabolism and excretion studies in ruminants. 13. Intake and utilization of wheat straw by sheep and cattle. Austr. J. Agric. Res. 25: 631-642.

Bouchard, R. \& Conrad, H. R. 1973. Sulfur requirement of lactating dairy cows. 1. Sulfur balance and dietary supplementation. J. Dairy Sci. 56: 1276-1282.

Chalupa, W., Oltjen, R. R., Slyter, L. L. \& Dinius, D. A. 1971. Sulfur deficiency and tolerance in bull calves. J. Anim. Sci. 33: 278 (Abstr.).

- - Oltjen, R. R. \& Dinius, D. A. 1973. Sulfur nutrition for urea fed cattle. J. Anim. Sci .37: 340 (Abstr.).

Elam, C. J. 1975. Sulfur requirement of ruminants. Feedstuffs, September 23-25.

Hintz, H. F. \& Hogue, D. E. 1964. Effect of selenium, sulfur and sulfur amino acids on nutritional muscular dystrophy in the lamb. J. Nutr. 82:495-498.

Huisingh, J., Gomez, G. G. \& Matrone, G. 1973. Interactions of copper, molybdenum, and sulfate in ruminant nutrition. Fed. Proc. 32: 1921-1924.

Korkмan, J. 1973. Sulphur status in Finnish cultivated soils. Selostus. Suomen viljelysmaiden rikkitila. Maatal. tiet. Aikak. 45: 121-215.

Lindfors, P., RauramaA, A., Hiltunen, A \& Kreula, M. 1976. Säilörehujen laatu syyskaudella 1975 otantatutkimuksen valossa. Karjatalous n:o 4, 9-11.

NJF. 1975. Förslag till normer för makro- och mikromineraler till nötkreaturen och svin. Foderjournalen 14: 55-104.

NRC. 1971. Nutrient requirement of dairy cattle. National Academy of Sci. Washington. D. C.

OKsANEN, H. E. 1965. Influence of sulphur on nutritional muscular degeneration (NMD) in ruminants. 2. Sulphur content in forage. Nord. Vet. Med. 17: 402-405.

Salonen, M., Keränen, T., TAinio, A. \& TÄHtınen, H. 1962. Alueellisia ja maaperästä johtuvia eroja timoteiheinän kivennäisainepitoisuuksissa. Ann. Agric. Fenn. 1: 226 -232 .

Käsikirjoitus saapunut 16.9.1976 